\title{
Facilitation of an invader by a native habitat-former increases along interacting gradients of environmental stress
}

\author{
Marc Uyà (D) ${ }^{1,2}$ Fabio Bulleri (D) $1,3,6$ Jeffrey T. Wright (D) ${ }^{4}$ and Paul E. Gribben (D) 2,5 \\ ${ }^{1}$ Dipartimento di Biologia, Università di Pisa, Via Derna 1, 56126 Pisa, Italy \\ ${ }^{2}$ Centre for Marine Science and Innovation, School of Biological, Earth and Environmental Sciences, University of New South Wales, \\ Sydney, 2052 New South Wales, Australia \\ ${ }^{3}$ CoNISMa, Consorzio Nazionale Interuniversitario per le Scienze del Mare, Piazzale Flaminio 9, 00196 Roma, Italy \\ ${ }^{4}$ Institute for Marine and Antarctic Studies, University of Tasmania, Private Bag 129, Hobart 7001 Australia \\ ${ }^{5}$ Sydney Institute of Marine Science, 19 Chowder Bay Road, Mosman, 2088 New South Wales, Australia
}

Citation: Uyà, M., F. Bulleri, J. T. Wright, and P. E. Gribben. 2020. Facilitation of an invader by a native habitat-former increases along interacting gradients of environmental stress. Ecology 101(4):e02961. 10. 1002/ecy.2961

Abstract. Native habitat-forming species can facilitate invasion by reducing environmental stress or consumer pressure. However, the intensity of one stressor along a local gradient may differ when expanding the scale of observation to encompass major variations in background environmental conditions. In this study, we determined how facilitation of the invasive porcelain crab, Petrolisthes elongatus, by the native tube-forming serpulid, Galeolaria caespitosa, varied with environmental gradients at local (tidal height) and larger (wave exposure) spatial scales. G. caespitosa constructs a complex calcareous matrix on the underside of intertidal boulders and we predicted that its positive effects on P. elongatus density would increase in intensity with shore height and be stronger at wave-sheltered than wave-exposed locations. To test these predictions, we conducted two experiments. First, we determined the effects of serpulid presence (boulders with live or dead serpulid matrix vs. bare boulders) at six shore heights that covered the intertidal distribution of $P$. elongatus. Second, we determined the effects of serpulid presence (present vs. absent), shore height (high vs. low) and wave exposure (sheltered vs. exposed) on crabs across six locations within the invaded range in northern Tasmania, Australia. In Experiment 1, the presence of serpulids (either dead or alive) enhanced $P$. elongatus densities at all shore heights, with facilitation intensity (as determined by a relative interaction index; RII) tending to increase with shore height. In Experiment 2, serpulids facilitated $P$. elongatus across shore heights and wave exposures, although crab densities were lower at high shore levels of wave-sheltered locations. However, the intensity of crab facilitation by serpulids was greater on wave-sheltered than on wave-exposed shores, but only at the high shore level. This study demonstrates that local effects of native habitat-formers on invasive species are dependent on prevailing environmental conditions at larger spatial scales and that, under more stressful conditions, invaders become increasingly reliant on positive interactions with native habitat-formers. Increased strength of local-scale facilitation by native species, dampening broader scale variations in environmental stressors, could enhance the ability of invasive species to establish self-sustaining populations in the invaded range.

Key words: biological invasion; environmental stress; facilitation; intertidal boulder field; Petrolisthes elongatus; positive interactions.

\section{INTRODUCTION}

The success of nonnative species in a new region is influenced by a range of factors, including the biotic and abiotic characteristics of invaded habitats (D'Antonio and Vitousek 1992, Stachowicz et al. 2002, Lockwood et al. 2013). Native species limit the establishment and spread of nonnative species through negative biotic interactions, such as competition (Davis et al. 2000,

Manuscript received 12 June 2019; revised 23 September 2019; accepted 11 November 2019. Corresponding Editor: Jonathan H. Grabowski.

${ }^{6}$ E-mail: fabio.bulleri@unipi.it
Kennedy et al. 2002, Stachowicz et al. 2002) or predation (Maron and Vila 2001, deRivera et al. 2005, Carlsson et al. 2009) and by controlling abiotic conditions (Davis et al. 2000, Lockwood et al. 2013, Gribben et al. 2018).

However, there is also evidence of native species facilitating the establishment and spread of nonnative species by reducing physical stress, consumer pressure or by increasing access to limiting resources (Cavieres et al. 2007, Ruesink 2007, Bulleri et al. 2008, Altieri et al. 2010, Northfield et al. 2018). An extensive body of work, motivated by the stress gradient hypothesis, demonstrates increases in the frequency and strength of 
facilitative interactions along abiotic stress gradients (Bertness and Callaway 1994, Callaway and Walker 1997, Brooker et al. 2006, Brooker 2008, He et al. 2013). Although examples are rare, the strength of facilitative effects of native species on invaders can also increase with environmental stress. For instance, facilitation of two exotic plants by the native cushion plant, Azorella monantha, was greater at higher compared to lower elevations (Badano et al. 2007), possibly because cushion plants have a relatively stronger effect on moderating temperature extremes and enhancing soil moisture content and nutrient availability at higher compared to lower elevations (Arroyo et al. 2003, Cavieres et al 2003, Badano et al. 2006).

Additionally, the strength of facilitation across a local stress gradient should be dependent on environmental variation occurring at larger spatial scales. For example, in a large-scale observational study at Marion Island, the positive effects of the cushion plant Azorella selago on the grass Agrostis magellanica generally increased with altitude, but, at a smaller scale, facilitation increased with wind exposure (Le Roux and McGeoch 2010). On intertidal rocky shores on the U.S. east coast, macroalgal canopies were found to facilitate barnacles at southern sites, but not under cooler climates at higher latitudes (Leonard 2000). Mechanisms of facilitation can also change as a function of environmental variation occurring at larger spatial scales. For example, along the east coast of Australia, oysters enhanced invertebrate diversity through shading in warmer estuaries, but through the provision of refuge against predation in cooler estuaries (McAfee and Bishop 2019). Nonetheless, few studies have experimentally investigated how facilitation of nonnative species by native habitat-forming species change along gradients of stress operating at multiple spatial scales.

Intertidal habitats are harsh environments and native habitat-forming species, including macrophytes (Leonard 2000, Altieri et al. 2010) or sessile invertebrates, such as barnacles, mussels, or tubeworms (Ruesink 2007, Altieri et al. 2010, Wright et al. 2018), can provide more benign conditions for native and nonnative species on local scales (centimeters to tens of centimeters) by buffering physical stress. For example, the combined presence of ribbed mussels (Geukensia demissa) and cordgrass (Spartina alterniflora) increased the density of the invasive Asian shore crab (Hemigrapsus sanguineus) in Narragansett Bay, USA, by reducing thermal stress and substrate instability (Altieri et al. 2010). Native habitat-formers can also reduce mechanical stress from wave action. For example, native mussels reduced the dislodgement of intertidal thalli of the invasive seaweed, Codium fragile ssp. tomentosoides, on wave-exposed breakwaters (Bulleri and Airoldi 2005). Indeed, although limited to the case of interactions between native species, single habitat-formers can buffer associated species from multiple stressors. For example, Kawai and Tokeshi (2004) showed that the goose barnacle
Capitulum mitella promoted the survivorship and growth of the mussel Septifer virgatus both in summer, by reducing thermal stress, and in winter, by dampening wave action.

The set of stressors operating in intertidal habitats vary on different scales and are likely to interact in ways that influence facilitative interactions between native habitat-forming species and nonnative species. At small scales (meters), individuals at different tidal heights are exposed to aerial conditions for different amounts of time at low tide, causing temperature and desiccation stress to increase with shore heights (Harley and Helmuth 2003, Finke et al. 2007, Silliman et al. 2011, Stickle et al. 2017). On the other hand, individuals at low-shore levels can be subjected to greater mechanical stress from wave action than those at upper shore levels (Denny 1995). However, at larger scales (kilometers), wave or wind exposure determines variations in hydrodynamic forces and, indirectly, in temperature and desiccation stress across tidal heights, via wave splashing and spray (McQuaid and Branch 1984, Denny 1995, Harley and Helmuth 2003, Fitzhenry et al. 2004, Davenport and Davenport 2005).

Petrolisthes elongatus, an introduced filter-feeding porcelain crab native to New Zealand, is widespread on intertidal rocky shores across Tasmania, Australia. $P$. elongatus lives underneath boulders, where it reaches adult densities $>1,800$ individuals $/ \mathrm{m}^{2}$. The abundance of P. elongatus varies among sites and shore heights, being generally higher on low to moderate wave energy shores (Gregory et al. 2012) and at low- to mid-shore tidal heights (Gribben et al. 2013). The habitat-forming serpulid tubeworm Galeolaria caespitosa forms a complex calcareous matrix on the underside of boulders (Wright et al. 2016) and was found to enhance the abundance of $P$. elongatus at two relatively wave-exposed sites (Wright et al. 2018). This facilitation is likely due to G. caespitosa reducing temperature underneath boulders during emersion at mid to high shore levels (Wright and Gribben 2017), but, possibly, also to the provisioning of safe habitat against mechanical disturbance by waves at lowshore heights (Wright et al. 2018). Thus, previous work suggests the intensity of stressors relevant to P. elongatus is likely to vary at both large (wave exposure) and small spatial scales (shore height). Nonetheless, how the strength of facilitation by $G$. caespitosa varies as a function of tidal height and wave exposure has not been determined, limiting our understanding of the interaction between native serpulids and invasive crabs at scales relevant to management. In this study, two field experiments were conducted to address this knowledge gap. More specifically, we tested predictions from alternative models considering how variations in major stressors (i.e., desiccation/temperature and hydrodynamic forces) across tidal heights could influence the strength of positive effects of $G$. caespitosa on the density of $P$. elongatus on wave-sheltered and wave-exposed rocky shores. 
In particular, we predicted that, because of decreased wave wash and spray on wave-sheltered rocky shores (McQuaid and Branch 1984, Harley and Helmuth 2003, Fitzhenry et al. 2004, Davenport and Davenport 2005), facilitation of crabs by serpulids through the buffering of temperature and desiccation stress (hereafter also referred to as environmental harshness) would increase in strength from low to high shore levels and be stronger in wave-sheltered in comparison to wave-exposed shores. On wave-exposed shores, wave action can be a stressor itself at low-shore heights, while reducing the severity of temperature and desiccation stress at upper levels through wave washing and spraying. Thus, the strength of facilitation of crabs by serpulids could remain similar across shore heights when both environmental harshness (at upper shore levels) and hydrodynamic forces (at lower shore levels) underpin positive effects of serpulids on crabs. However, when amelioration of environmental harshness is the main determinant of the facilitative interaction, a moderate increase in the strength of facilitation from low to high shore levels is predicted. In contrast, when buffering from hydrodynamic forces underpins the facilitation of crabs by serpulids the strength of facilitation could be expected to decrease from low to high shore levels.

\section{Materials And Methods}

\section{Study site and species}

This study was performed at intertidal boulder fields along the northern coast of Tasmania during the summers of 2017 and 2018 (Fig. 1). These sites were generally characterized by low energy, but varied in their exposure (Wright et al. 2018). The tidal range at these sites varies from a low of $0.25 \mathrm{~m}$ to a high of $3.6 \mathrm{~m}$. All locations had a north or northeast orientation, except Low Head River (LHR), which was northwest, and all were characterized by dolerite rock from the Parmeneer deposit group (Wright et al. 2018). On these shores, the native habitat-forming serpulid Galeolaria caespitosa colonizes space underneath boulders, generating a complex, three-dimensional surface (Wright et al. 2016). The maximum air temperature at these sites during the daytime in summer is typically between $17-25^{\circ} \mathrm{C}$ but can be $>30^{\circ} \mathrm{C}$. Importantly, the presence of serpulids reduces temperatures beneath boulders by up to $6^{\circ} \mathrm{C}$ compared to boulders where the serpulids are absent (Wright and Gribben 2017). At the study sites, the invasive crab Petrolisthes elongatus, possibly introduced via live oyster trade during the late 1800 s, reaches high densities underneath boulders and among cobbles at low- to mid-tide heights (Gregory et al. 2012, Gribben et al. 2013, 2015, Wright et al. 2018). P. elongatus co-occurs with a diverse assemblage of intertidal invertebrates (Gribben et al. 2015).

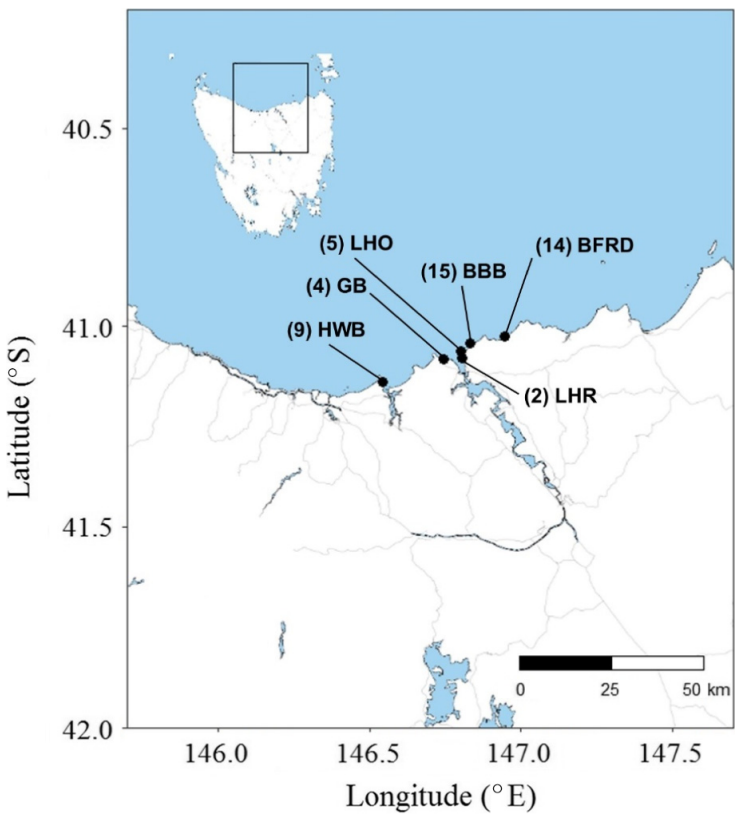

FIG. 1. Map of the study locations in northern Tasmania, Australia. Abbreviations are BBB (Bell Buoy beach), BFRD (Beechford), GB (Greens beach), HWB (Hawley beach), LHO (Low Head Ocean), and LHR (Low Head River). The number beside the abbreviated location name corresponds to the Baardseth Index. Map tiles were sourced from Stamen Design (2016).

\section{Experiment 1: Variation in the effects of serpulids on invasive crabs with shore height}

We experimentally tested the effects of shore height (six levels; 0.7, 1, 1.3, 1.6, 1.9 and $2.2 \mathrm{~m}$ above mean lower low water, hereafter MLLW) and presence of serpulids (three levels; boulders without G. caespitosa, boulders with live G. caespitosa tubes, and boulders with dead G. caespitosa tubes) on the density of P. elongatus. This experiment was conducted at Bell Buoy beach, a site of relatively high wave exposure (Fig. 1) and lasted for three weeks, from mid-January to early February 2017. Initially, using the Emery method (Emery 1961), we estimated that the intertidal zone where both $P$. elongatus and G. caespitosa were present was $150 \mathrm{~cm}$ in tidal height, which equated to a distance of $105 \mathrm{~m}$ up the shore. We divided the shore into six vertical sections and boulders were deployed every $30 \mathrm{~cm}$ of shore height. Boulders with live and dead tubes were included in the experiment to establish whether the effects of the serpulids were physical and/or biological in nature (Crooks and Khim 1999). Both live (Wright et al. 2018) and dead (Wright et al. 2016) tubes increase P. elongatus abundance but they have not been tested at the same time. Care was taken to only collect boulders in which the tube matrix covered a minimum $70 \%$ of the bottom of the boulders. We attempted to collect boulders of similar sizes, although we did not determine their surface area until the end of the experiment (see this section below). 
Dead tubes were obtained by placing upturned boulders above the high tide line for $48 \mathrm{~h}$.

Before deployment, all large biota (e.g. chitons, sponges, algae, mussels, and snails) remaining on the dried boulders were carefully scraped off the surface of G. caespitosa using a knife, taking care to not damage the serpulid matrix. At each shore height, boulders were then haphazardly deployed (six replicates for each combination of shore height and serpulid treatment) and treatments interspersed at least $1 \mathrm{~m}$ apart on a bottom of bedrock and/or bedrock with cobbles, the most suitable underlying habitats for P. elongatus (Gribben et al. 2015, Wright et al. 2018). All P. elongatus were removed from experimental areas before boulder deployment to avoid any possible bias due to initial differences in crab numbers. Boulders were marked on the top with paint to find them in subsequent visits.

At the end of the experiment, the abundance of $P$. elongatus under each boulder was estimated through slow-motion video capture, set at 30 frames per second in 720p format (Wright et al. 2018). A photograph was then taken of the underside of each boulder to quantify boulder surface area. Similar to that described in Wright and Gribben (2017), the surface area of boulders ranged from 440 to $1,600 \mathrm{~cm}^{2}$. We calculated the density of P. elongatus (individuals $/ \mathrm{cm}^{2}$ of boulder surface area) under each boulder as we had boulders of different sizes and P. elongatus abundance is significantly related to boulder surface area (Gribben et al. 2015).

A relative interaction index (RII; Armas et al. 2004) was also used to assess the sign and intensity of the effects of G. caespitosa on P. elongatus. The RII was expressed as RII $=\left(B_{\mathrm{w}}-B_{0}\right) /\left(B_{\mathrm{w}}+B_{0}\right)$ where $B_{\mathrm{w}}$ and $B_{0}$ represent the density of $P$. elongatus in the presence (live and dead G. caespitosa combined) and absence of $G$. caespitosa, respectively. $B_{0}$ was calculated as the average density of $P$. elongatus beneath boulders without G. caespitosa, separately for each shore height.

The effects of shore height and presence of serpulids (both fixed factors) on the density of $P$. elongatus were analyzed with a two-factor ANOVA and the effects of shore height (fixed) on RII was analyzed with a one-way ANOVA. Only 4 of 16 boulders in the uppermost shore treatment (2.2. $\mathrm{m}$ above MLLW) were recovered, so this shore height was excluded from the analyses. The abundances of crabs recovered from these four boulders was very low (range 0-6 per boulder). Four boulders were lost at other shore heights, and missing values were replaced with the means, adjusting the degrees of freedom of the residual accordingly (Underwood 1997). For RII, data for all boulders with serpulids present were pooled as no significant differences for $P$. elongatus density were observed between live and dead boulders (see Results). Homogeneity of variances were checked using Cochran's test. SNK tests were used for post hoc comparison of the means. ANOVA tests were performed in $\mathrm{R}$ using the gad function within the GAD package (Sandrini-Neto and Camargo 2012).

\section{Experiment 2: Variation in the effects of serpulids on} nonnative crabs with wave exposure and shore height

We experimentally tested the effects of wave exposure (two levels; wave-exposed shores, with a Baardseth index $\geq 9$, or wave-sheltered shores, with a Baardseth index $\leq 5$; Baardseth 1970; see Wright et al. 2018; Fig. 1), shore height (two levels; 0.9 and $1.6 \mathrm{~m}$ above the MLLW) and the presence of serpulids (two levels; boulders with or without G. caespitosa) on the density of P. elongatus. There were three locations for each wave exposure category (Fig. 1) and the experiment lasted for four weeks, from February to March 2018. Temperature loggers (HOBO MX2202 Pendant MX Temperature/Light Data Logger; Onset, Bourne, MA, USA) placed beneath boulders at all locations/shore heights/serpulid treatments during the experiment indicated only slight differences in average temperatures during emersion between wave-sheltered and wave-exposed shores $\left(1.6 \mathrm{~m}\right.$ above MLLW, $0.72^{\circ} \pm 0.12^{\circ} \mathrm{C}$ hotter on wave-sheltered shores, mean $\pm \mathrm{SE}, N=24 \mathrm{~d}$; $0.9 \mathrm{~m}$ above MLLW, $0.15^{\circ} \pm 0.15^{\circ} \mathrm{C}$ hotter on wavesheltered, mean $\pm \mathrm{SE}, N=24 \mathrm{~d}$, pooled across locations and serpulid treatments for each shore height). However, based on tidal data for one location (LHO), boulders at $1.6 \mathrm{~m}$ were exposed to the air during daylight for an average of $372.5 \pm 11.3$ (mean \pm SE) minutes/d (range 300-480 minutes, $N=24$ d) while boulders at $0.9 \mathrm{~m}$ were exposed for an average of $178 \pm 13.0$ (mean $\pm \mathrm{SE}$ ) minutes/d (range 30-270 minutes). The loggers did not detect a large reduction in temperature by serpulids, as measured previously using an infrared thermometer (Wright and Gribben 2017). This was likely because the loggers used here are $1.8 \mathrm{~cm}$ thick resulting in boulders no longer sitting flat on the underlying substrate, allowing air circulation beneath the boulders, which may have dampened the cooling effects of serpulids.

Methods for the identification of the shore height and experimental boulder deployment were as described for Experiment 1. Boulders with dead serpulids were not included due to no differences in P. elongatus densities between boulders with live and dead G. caespitosa in Experiment 1 (see Results). Since we observed large variability among replicates in Experiment 1, replication for each shore height $\times$ serpulid treatment was increased to eight boulders per location. Boulder surface area and P. elongatus density beneath each boulder were determined as described for Experiment 1.

Differences in the density of $P$. elongatus among treatments was analyzed using a four-factor ANOVA with shore height, presence of serpulids, and wave exposure as fixed, crossed factors, and location as a random factor nested within wave exposure. Ten replicates, scattered across different combinations of location, serpulid treatment, and shore height, were lost and missing values were replaced with means, following the same procedure 
described for Experiment 1. Although homogeneity of variances could not be achieved for density, ANOVA is robust to the departure of this assumption when there are many independent and balanced replicates (Underwood 1997). However, in order to mitigate a potential bias due to inflated Type I error, significance of tests was interpreted with caution by setting $\alpha=0.01$. RII was analyzed using a three-factor ANOVA with shore height and wave exposure as fixed, crossed factors, and location as a random factor nested within wave exposure. Pooling procedures were also used as recommended by Underwood (1997) in order to enhance the power of statistical tests. More specifically, in the analysis of RII in Experiment 2 , the term shore height $\times$ location(wave exposure) was not significant at $P=0.25$ and was removed from the analyses, allowing the $F$ test for the interaction shore height $\times$ wave exposure to be carried out using the residual term as the denominator.

\section{RESULTS}

\section{Experiment 1: Variation in the effects of serpulids on invasive crabs with shore height}

There was no significant difference in the density of Petrolisthes elongatus among shore heights (Fig. 2A; Table 1A). The density of $P$. elongatus was, however, higher below boulders with serpulids than below boulders without serpulids, while it did not differ between live or dead serpulid treatments (Fig. 2A; Table 1A). Although there was no significant interactive effect of shore height and serpulid treatment, the density of P. elongatus tended to be lower in the absence of serpulids at 1.6 and $1.9 \mathrm{~m}$ above the MLLW (Fig. 2A; Table 1A). There was a trend for RII to become more positive at heights on the shore greater than $1.3 \mathrm{~m}$ above MLLW, although there was no significant difference among shore heights (Fig. 2B; Table 1B).

\section{Experiment 2: Variation in the effects of serpulids on invasive crabs with wave exposure and shore height}

We detected a significant interaction between shore height and location for P. elongatus density: at two (LHO and LHR) of the three sheltered locations, the density of crabs was higher at 0.9 than $1.6 \mathrm{~m}$ above MLLW, while it did not differ between heights at the three wave-exposed locations (Fig. 3; Table 2A). Similar to Experiment 1, the density of $P$. elongatus was higher below boulders with serpulids than without serpulids (Fig. 3; Table 2A).

The RII was generally positive at wave-exposed and wave-sheltered locations (Fig. 4). However, there was a significant interaction between shore height and wave exposure for RII: at wave-sheltered locations, the intensity of positive effects of serpulids on P. elongatus was greater at 1.6 than $0.9 \mathrm{~m}$ above MLLW, while it did not differ between shore heights on wave-exposed shores
A

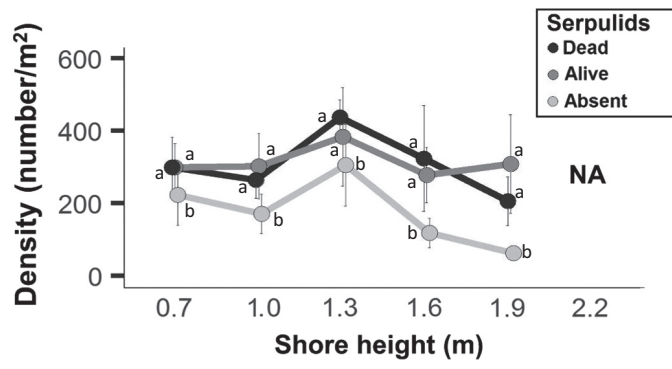

B

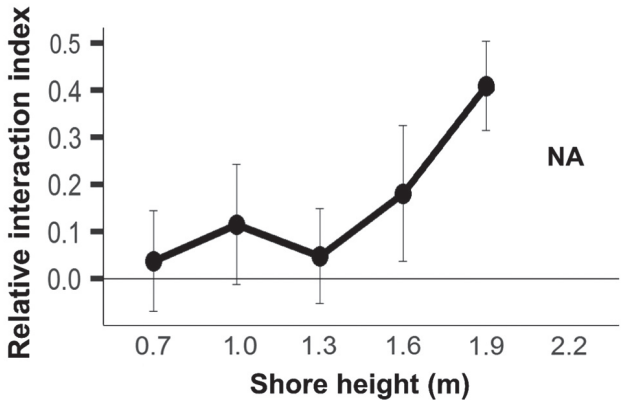

FIG. 2. (A) Density of the nonnative crab Petrolisthes elongatus under boulders in the presence (dead and alive) and absence of native serpulid Galeolaria caespitosa on the underside of boulders $(N=6)$ across shore heights at Bell Buoy beach. (B) Relative interaction index showing the effect of facilitation by G. caespitosa on P. elongatus. For the relative interaction index, dead and alive serpulid treatments were pooled $(N=12)$. Plots show the mean $\pm \mathrm{SE}$. No values are presented for the uppermost shore height as only four boulders were retrieved with no replicates for some treatments. Different letters beside symbols indicate significant differences $(P<0.05)$ from post hoc tests reported in Table 1A.

TABLE 1. Experiment 1: ANOVA testing (A) the effects of serpulids (three levels; serpulids alive, dead, and absent) and shore height (five levels) on the density of Petrolisthes elongatus and (B) the effects of shore height on the relative interaction index (RII) at Bell Buoy Beach.

\begin{tabular}{lccc}
\hline \hline Source of variation & df & MS & $F$ \\
\hline (A) Petrolisthes elongatus density & & \\
Serpulids (S) $\dagger$ & 2 & 179445 & $3.813^{*}$ \\
Shore height (H) & 4 & 82699 & 1.757 \\
S $\times$ H & 8 & 11674 & 0.248 \\
Residual & 71 & 46402 & \\
(B) Relative interaction index (RII) & & \\
Shore height (H) & 4 & 0.276 & 1.747 \\
Residual & 54 & 0.158 & \\
\hline
\end{tabular}

Notes: Analyses on untransformed data; Cochran's test $P>0.05$. For the RII, data were pooled for live and dead serpulids.

${ }^{*} P<0.05$.

$\dagger$ Post hoc Student-Newman-Keuls (SNK) test: alive $=$ dead $>$ absent.

(Fig. 4; Table 2B). The strength of positive effects of serpulids on crabs was greater at wave-sheltered than waveexposed locations at $1.6 \mathrm{~m}$ above MLLW, while there was no difference lower on the shore (Fig. 4; Table 2B). 
A) Wave-sheltered

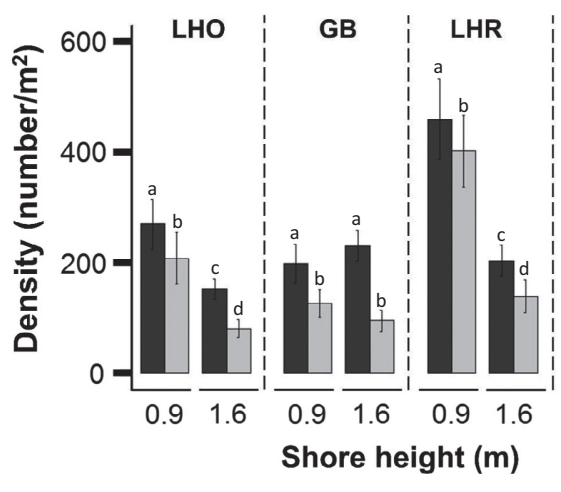

B) Wave-exposed

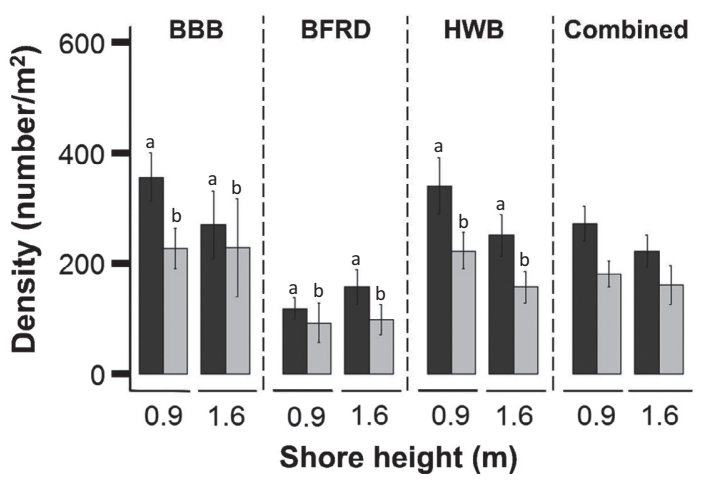

FIG. 3. Density (mean $\pm \mathrm{SE}$ ) of the nonnative crab Petrolisthes elongate under boulders in the presence and absence of the native serpulid Galeolaria caespitosa at two shore heights at (A) wave-sheltered and (B) wave-exposed locations. Location abbreviations are as in Fig. 1. Different letters above bars indicate significant differences $(P<0.05)$ from post hoc tests reported in Table 2A.

\section{DisCUSSION}

Amelioration of environmental stress by habitat-formers can promote the establishment and persistence of species in otherwise unsuitable habitats (Bruno et al. 2003). In line with our prediction, the native serpulid Galeolaria caespitosa enhanced the density of the invasive crab Petrolisthes elongatus consistently across shore heights and on both wave-exposed and wave-sheltered shores. Moreover, the intensity of positive effects of serpulids on crabs was greater on wave-sheltered than on wave-exposed shores, but only at the high shore level.

Our results expand on previous studies (Wright et al. 2016, 2018) by showing that serpulids beneath boulders can increase $P$. elongatus densities throughout most of the tidal range over which they occur. Although most of the boulders at $2.2 \mathrm{~m}$ above MLLW were not retrieved at the end of the study, very low densities of $P$. elongatus indicate that shore heights $>1.9 \mathrm{~m}$ above MLLW are extremely stressful and result in very low population abundances even in the presence of serpulids. Thus,
TABLE 2. Experiment 2: ANOVA testing (A) the effects of serpulids (two levels: present and absent), shore height (two levels; 0.9 and $1.6 \mathrm{~m}$ above MLLW), wave exposure (two levels; sheltered and exposed), and location (three levels, nested within wave exposure) on the density of Petrolisthes elongatus and (B) the effects of shore height, wave exposure, and location on the relative interaction index (RII).

\begin{tabular}{|c|c|c|c|}
\hline Source of variation & $\mathrm{df}$ & MS & $F$ \\
\hline \multicolumn{4}{|c|}{ (A) Petrolisthes elongatus density } \\
\hline Serpulids (S) & 1 & 289310.0 & $46.540 * *$ \\
\hline Shore height $(\mathrm{H})$ & 1 & 306697.0 & 3.939 \\
\hline Wave exposure (E) & 1 & 487.0 & 0.002 \\
\hline $\mathrm{S} \times \mathrm{H}$ & 1 & 0.1 & 0.001 \\
\hline $\mathrm{S} \times \mathrm{E}$ & 1 & 4.0 & 0.001 \\
\hline $\mathrm{H} \times \mathrm{E}$ & 1 & 106951.0 & 1.374 \\
\hline Location $(\mathrm{E})=\mathrm{L}(\mathrm{E})$ & 4 & 200659.0 & $13.677 * *$ \\
\hline $\mathrm{S} \times \mathrm{H} \times \mathrm{E}$ & 1 & 8374.0 & 1.761 \\
\hline $\mathrm{S} \times \mathrm{L}(\mathrm{E})$ & 4 & 6216.0 & 0.424 \\
\hline $\mathrm{H} \times \mathrm{L}(\mathrm{E}) \dagger$ & 4 & 77868.0 & $5.308 * *$ \\
\hline $\mathrm{S} \times \mathrm{H} \times \mathrm{L}(\mathrm{E})$ & 4 & 4754.0 & 0.324 \\
\hline Residual & 158 & 14671.7 & \\
\hline \multicolumn{4}{|c|}{ (B) Relative interaction index (RII) } \\
\hline Shore height $(\mathrm{H})$ & 1 & 0.043 & 0.76 \\
\hline Wave exposure (E) & 1 & 0.235 & 1.73 \\
\hline $\mathrm{H} \times \mathrm{E} \S$ & 1 & 0.276 & $4.89 *$ \\
\hline Location $(\mathrm{E})=\mathrm{L}(\mathrm{E})$ & 4 & $0.136 \%$ & 2.41 \\
\hline $\mathrm{H} \times \mathrm{L}(\mathrm{E})$ & 4 & 0.058 & Eliminated \\
\hline Residual & 79 & 0.056 & \\
\hline
\end{tabular}

Notes: Analyses on untransformed data; Cochran's test for (A) $P<0.05$ and for (B) $P>0.05$.

$* P<0.05$.

$* * P<0.01$.

$\uparrow$ Post hoc Student-Newman-Keuls (SNK) tests; wave-exposed, BBB, $0.9 \mathrm{~m}=1.6 \mathrm{~m}$ : BFRD, $1.6 \mathrm{~m}=0.9 \mathrm{~m}$; HWB, $0.9 \mathrm{~m}=1.6 \mathrm{~m}$; wave-sheltered, GB, $0.9 \mathrm{~m}=1.6 \mathrm{~m}$; LHO, $0.9 \mathrm{~m}>1.6 \mathrm{~m}$; LHR, $0.9 \mathrm{~m}>1.6 \mathrm{~m}$. Location abbreviations are BBB (Bell Buoy beach), BFRD (Beechford), GB (Greens beach), HWB (Hawley beach), LHO (Low Head Ocean), and LHR (Low Head River).

$\ddagger$ Tested on the residual.

$\S$ Post hoc Student-Newman-Keuls (SNK) tests; wave-exposed $0.9 \mathrm{~m}=1.6 \mathrm{~m}$; wave-sheltered $1.6 \mathrm{~m}>0.9 \mathrm{~m} ; 0.9 \mathrm{~m}$ wave-exposed $=$ wave-sheltered; $1.6 \mathrm{~m}$ wave-sheltered $>$ waveexposed.

G. caespitosa could ameliorate environmental conditions only up to a stress threshold. This finding is similar to previous studies showing that there are limits to facilitation and that, beyond a given threshold of stress, positive interactions are likely to fade (Michalet et al. 2006, Holmgren and Scheffer 2010, Qi et al. 2018, Zhang et al. 2018).

Below that threshold, the intensity of benefits delivered to crabs tended to be greater at upper levels on the shore (i.e., 1.6-1.9 $\mathrm{m}$ above MLLW), suggesting that the presence of serpulids is key for the persistence of crabs under those harsher environmental conditions. At lowshore levels, thermal stress is less likely to be the major factor limiting crab densities due to frequent splashing and shorter exposure to the air. Similar research on congeneric species suggests that intertidal Petrolisthes spp. 
A) Wave-sheltered

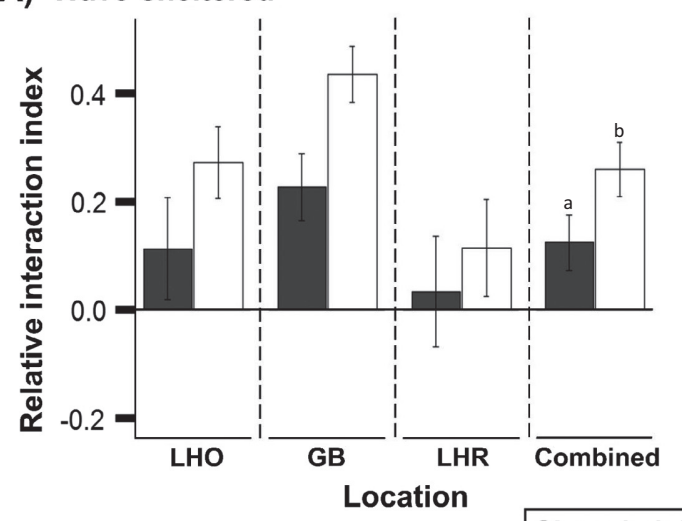

\section{B) Wave-exposed}

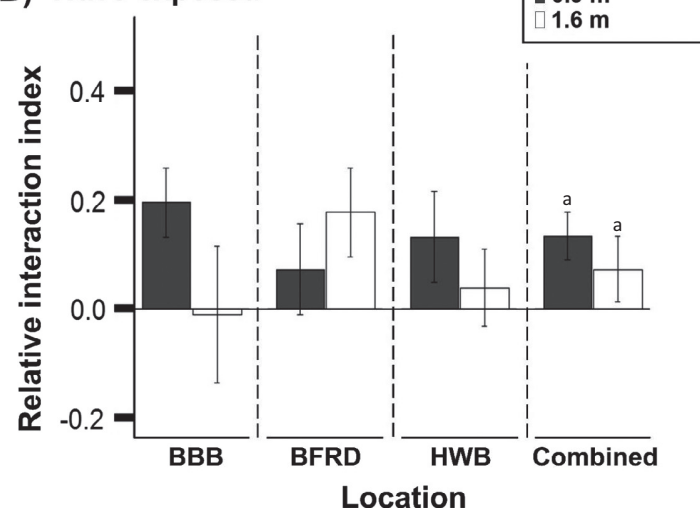

FIG. 4. Relative interaction index (mean $\pm \mathrm{SE}$ ) showing the effect of facilitation by G. caespitosa on P. elongatus between two shore heights at (A) wave-sheltered and (B) wave-exposed locations. Location abbreviations are as in Fig. 1. Different letters above bars indicate significant differences $(P<0.05)$ from post hoc tests reported in Table 2B.

are sensitive to thermal stress at low tides and may currently be living near their upper thermal tolerance limit (Jensen and Armstrong 1991, Stillman and Somero 2000). Higher densities of $P$. armatus in low-shore habitats at sites it has invaded in Georgia, USA, could be explained by high desiccation and heat stress at upper shore levels in summer months (Hollebone and Hay 2007).

Previous studies of marine habitat-forming species have also shown that positive effects of native on invasive species are often physical in nature (Ruesink 2007, Altieri et al. 2010, Silliman et al. 2011). For example, Bulleri and Benedetti-Cecchi (2008), using plastic mimics, have shown that algal turfs facilitate the invasive seaweed, Caulerpa cylindracea, by providing a complex surface for the anchoring of rhizoids. Likewise, canopies of the native seagrass, Zostera marina, facilitate the establishment of Sargassum muticum on soft bottoms by trapping drifting fragments of the alga (Tweedley et al. 2008). The absence of differences in the effects between the live and dead serpulid matrix indicates that the animals inhabiting the tubes do not play a role in generating positive effects on $P$. elongatus. As such, mortality of serpulids would not reduce their ability to deliver benefits to crabs, as long as their shells remain intact. Indeed, the calcareous matrix formed by tubes can persist long after the animals' death (e.g., tens of years), making this biogenic habitat a highly reliable refuge for crabs (Hughes 2011). Autogenic ecosystem engineers are predicted to have lasting legacy effects on associated organisms when the structure they provide persists after they die (Jones et al. 1994).

Our second experiment indicates that the intensity of the effects of serpulids on P. elongatus would be equally important at the low-shore heights $(0.9 \mathrm{~m}$ above MLLW) irrespective of wave exposure, but were greater at high shore heights at wave-sheltered compared to wave-exposed sites.

Although weak, the effects of serpulids on crabs remained positive even in low-shore habitats. At lowshore heights on wave-exposed shores, serpulids may reduce the movement of boulders by waves or allow for firmer attachment, thus reducing mortality due to crushing or dislodgement by waves. At low-shore heights on wave-sheltered shores, reducing mortality due to predation may also contribute to facilitation of crabs by G. caespitosa. Predation pressure is generally more intense on wave-sheltered shores, where wave activity does not constrain foraging bouts (Menge and Sutherland 1987, Menge and Branch 2001) and the complex matrix formed by serpulids could provide crabs with shelter from predators, such as seastars, fish, and birds (Wright et al. 2018). These patterns may indicate that one single native species could increase the local abundance of a nonnative species through the mitigation of multiple stressors. Previous studies have demonstrated that one species can facilitate another by mitigating different, temporally or spatially segregated stressors. For example, Kawai and Tokeshi (2004) found that goose barnacles facilitated the mussel Septifer virgatus, by reducing thermal stress and wave action, in winter and summer, respectively. Likewise, in Australian estuaries, oysters sustained invertebrate diversity by buffering them from temperature stress at warmer sites and through the provision of refuge against predation at cooler ones (McAfee and Bishop 2019).

By contrast, even relatively small differences in wave exposure can modify the strength of the effects of serpulids on P. elongatus at upper shore levels. Slightly higher mean temperatures, combined with approximately double the amount of time exposed to the air, indicates increasingly stressful conditions in high tidal zones. Bare boulders still represent relatively safe refuges from increased harshness of environmental conditions at wave-exposed, but less so at wave-sheltered locations. Facilitation by serpulids, therefore, plays, a more important role in sustaining densities of $P$. elongatus under the harsh conditions that characterize the upper shore levels of wave-sheltered locations. Thus, local-scale stress buffering from serpulids across shore heights dampens 
larger scale variation in stress intensity due to wave exposure.

More broadly, our study, while adding to the growing body of literature documenting positive effects of native habitat-formers on invasive species, shows that the effects of a habitat-forming species in buffering local stressors are framed within background environmental conditions and, hence, likely to vary when expanding the scale of observation. Although the need for accounting for different types of stressors and their interaction is widely acknowledged (Kawai and Tokeshi 2004, 2006, Maestre et al. 2009a, Le Roux and McGeoch 2010, Bulleri et al. 2011), the overwhelming majority of facilitation studies have only taken into account single stress gradients, which assumes that the sign and magnitude of species interactions are under control of one overarching stressor. Few experimental studies encompassed stressors operating at different spatial scales (Maestre et al. 2009b, Le Roux and McGeoch 2010). In the study by Le Roux and McGeoch (2010), variations in the intensity of positive effects of the cushion plant Azorella selago on the grass Agrostis magellanica along the wind-exposure gradient and altitude gradients were independent. By contrast, our study highlights the interactive nature of the environmental factors that regulate species interactions. This finding is of particular relevance in the field of biological invasions since neglecting scale-dependent variations in the sign and magnitude of the effects of native biota on invaders may misguide management and control efforts. Finally, considering the interactive nature of multiple stressors may help resolving the ongoing debate on the generality of predictions of the SGH across natural systems (Maestre et al. 2005, Lortie and Callaway 2006, He and Bertness 2014).

\section{ACKNOWLEDGMENTS}

We would like to thank Daniel Estévez Barcia, Georgina Wood, Tenzin Norzin, and Chloe Wilson for help in the field. We would also like to thank Mira van der Ley and David Edwards for their helpful advice to perform the topographic profiles. The final version of the paper has been improved by insightful comments from two anonymous reviewers. P. E. Gribben was funded under the Australian Research Council Future Fellowship scheme (FT140100322). M. Uyà, P. E. Gribben, J. T. Wright, and F. Bulleri conceived the main ideas. $\mathrm{M}$. Uyà performed field work and the statistical analysis. F. Bulleri leaded the writing of the manuscript and all authors commented on drafts.

\section{Literature Cited}

Altieri, A. H., B. K. van Wesenbeeck, M. D. Bertness, and B. R. Silliman. 2010. Facilitation cascade drives positive relationship between native biodiversity and invasion success. Ecology 91:1269-1275.

Armas, C., R. Ordiales, and F. Pugnaire. 2004. Measuring plant interaction: a new comparative index. Ecology 85:2682-2686.

Arroyo, M. T. K., L. A. Cavieres, A. Peñaloza, and M. A. Arroyo-Kalin. 2003. Positive associations between the cushionplant Azorella monantha (Apiaceae) and alpine plant species in the Chilean Patagonian Andes. Plant Ecology 169:121-129.
Baardseth, E. M. 1970. Square-scanning, two-stage sampling method of estimating seaweed quantities. Norwegian Institute of Seaweed Research 33:1-41.

Badano, E. I., C. G. Jones, L. A. Cavieres, and J. P. Wright. 2006. Assessing impacts of ecosystem engineers on community organization: a general approach illustrated by effects of a high-Andean cushion plant. Oikos 115:369-385.

Badano, E. I., E. Villarroel, R. O. Bustamantes, P. A. Marquet, and L. A. Cavieres. 2007. Ecosystem engineering facilitates invasions by exotic plants in high-Andean ecosystems. Journal of Ecology 95:682-688.

Bertness, M. D., and R. Callaway. 1994. Positive interactions in communities. Trends in Ecology \& Evolution 9:191-193.

Brooker, R. W., et al. 2008. Facilitation in plant communities: the past, the present, and the future. Journal of Ecology 96:18-34.

Brooker, R., D. Scott, S. Palmer, and E. Swaine. 2006. Transient facilitative effects of heather on Scots pine along a grazing disturbance gradient in Scottish moorland. Journal of Ecology 94:637-645.

Bruno, J. F., J. J. Stachowicz, and M. D. Bertness. 2003. Inclusion of facilitation into ecological theory. Trends in Ecology and Evolution 18:119-125.

Bulleri, F., and L. Airoldi. 2005. Artificial marine structures facilitate the spread of a non-indigenous green alga, Codium fragile ssp. tomentosoides, in the north Adriatic Sea. Journal of Applied Ecology 42:1063-1072.

Bulleri, F., and L. Benedetti-Cecchi. 2008. Facilitation of the introduced green alga Caulerpa racemosa by resident algal turfs: experimental evaluation of underlying mechanisms. Marine Ecology Progress Series 364:77-86.

Bulleri, F., J. F. Bruno, and L. Benedetti-Cecchi. 2008. Beyond competition: Incorporating positive interactions between species to predict ecosystem invasibility. Plos Biology 6:11361140 .

Bulleri, F., C. Cristaudo, T. Alestra, and L. Benedetti-Cecchi. 2011. Crossing gradients of consumer pressure and physical stress on shallow rocky reefs: a test of the stress-gradient hypothesis. Journal of Ecology 99:335-344.

Callaway, R. M., and L. R. Walker. 1997. Competition and facilitation: a synthetic approach to interactions in plant communities. Ecology 78:1958-1965.

Carlsson, N. O. L., O. Sarnelle, and D. L. Strayer. 2009. Native predators and exotic prey-an acquired taste? Frontiers in Ecology and the Environment 7:525-532.

Cavieres, L. A., A. Peñaloza, and M. A. Arroyo-Kalin. 2003. Positive associations between the cushion plant Azorella monantha (Apiaceae) and alpine plant species in the Chilean Patagonian Andes. Plant Ecology 169:121-129.

Cavieres, L. A., E. I. Badano, A. Sierra-Almeida, and M. A. Molina-Montenegro. 2007. Microclimatic modifications of cushion plants and their consequences for seedling survival of native and non-native herbaceous species in the high Andes of Central Chile. Arctic, Antarctic, and Alpine Research 39:229-236.

Crooks, J. A., and H. S. Khim. 1999. Architectural vs. biological effects of a habitat-altering, exotic mussel, Musculista senhousia. Journal of Experimental Marine Biology and Ecology 240:53-75.

D’Antonio, C. M., and P. M. Vitousek. 1992. Biological invasions by exotic grasses, the grass fire cycle, and global change. Annual Review of Ecology and Systematics 23:63-87.

Davenport, J., and J. L. Davenport. 2005. Effects of shore height, wave exposure and geographical distance on thermal niche width of intertidal fauna. Marine Ecology Progress Series 292:41-50.

Davis, M. A., J. P. Grime, and K. Thompson. 2000. Fluctuating resources in plant communities: a general theory of invasibility. Journal of Ecology 88:528-534. 
Denny, M. W. 1995. Predicting physical disturbance: mechanistic approaches to the study of survivorship on wave-swept shores. Ecological Monographs 65:371-418.

deRivera, C. E., G. M. Ruiz, A. H. Hines, and P. Jivoff. 2005. Biotic resistance to invasion: Native predator limits abundance and distribution of an introduced crab. Ecology 86:3364-3376.

Emery, K. O. 1961. A simple method of measuring beach profiles. Limnology and Oceanography 6:90-93.

Finke, G. R., S. A. Navarrete, and F. Bozinovic. 2007. Tidal regimes of temperate coasts and their influences on aerial exposure for intertidal organisms. Marine Ecology Progress Series 343:57-62.

Fitzhenry, T., P. M. Halpin, and B. Helmuth. 2004. Testing the effects of wave exposure, site, and behavior on intertidal mussel body temperatures: applications and limits of temperature logger design. Marine Biology 145:339-349.

Gregory, L. P., M. L. Campbell, C. Primo, and C. L. Hewitt. 2012. Biotic and abiotic factors affecting the Tasmanian distribution and density of the introduced New Zealand porcelain crab Petrolisthes elongatus. Aquatic Invasions 7:491-501.

Gribben, P. E., S. I'Ons, N. E. Phillips, S. W. Geange, J. T. Wright, and B. R. Murray. 2013. Biogeographic comparisons of the traits and abundance of an invasive crab throughout its native and invasive ranges. Biological Invasions 15:18771885.

Gribben, P. E., M. Simpson, and J. T. Wright. 2015. Relationships between an invasive crab, habitat availability and intertidal community structure at biogeographic scales. Marine Environmental Research 110:124-131.

Gribben, P. E., T. Thomas, A. Pusceddu, L. Bonechi, S. Bianchelli, E. Buschi, S. Nielsen, C. Ravaglioli, and F. Bulleri. 2018. Below-ground processes control the success of an invasive seaweed. Journal of Ecology 106:2082-2095.

Harley, C. D. G., and B. S. T. Helmuth. 2003. Local- and regional-scale effects of wave exposure, thermal stress, and absolute versus effective shore level on patterns of intertidal zonation. Limnology and Oceanography 48:1498-1508.

He, Q., and M. D. Bertness. 2014. Extreme stresses, niches, and positive species interactions along stress gradients. Ecology 95:1437-1443.

He, Q., M. D. Bertness, and A. H. Altieri. 2013. Global shifts towards positive species interactions with increasing environmental stress. Ecology Letters 16:695-706.

Hollebone, A. L., and M. E. Hay. 2007. Population dynamics of the non-native crab Petrolisthes armatus invading the South Atlantic Bight at densities of thousands $\mathrm{m}^{-2}$. Marine Ecological Progress Series 336:211-223.

Holmgren, M., and M. Scheffer. 2010. Strong facilitation in mild environments: the stress gradient hypothesis revisited. Journal of Ecology 98:1269-1275.

Hughes, D. J. 2011. Where's the 'reef'? A five year study of serpulid tube bioerosion in a Scottish sea loch. Marine Ecology Progress Series 430:273-280.

Jensen, G. C., and D. A. Armstrong. 1991. Intertidal zonation among congeners: factors regulating distribution of porcelain crabs Petrolisthes spp. (Anomura: Porcellanidae). Marine Ecology Progress Series 73:47-60.

Jones, C. G., J. H. Lawton, and M. Shachak. 1994. Organisms as ecosystem engineers. Oikos 69:373-386.

Kawai, T., and M. Tokeshi. 2004. Variable modes of facilitation in the upper intertidal: goose barnacles and mussels. Marine Ecology Progress Series 272:203-213.

Kawai, T., and M. Tokeshi. 2006. Asymmetric coexistence: bidirectional abiotic and biotic effects between goose barnacles and mussels. Journal of Animal Ecology 75:928-941.
Kennedy, T. A., S. Naeem, K. M. Howe, J. M. H. Knops, D. Tilman, and P. Reich. 2002. Biodiversity as a barrier to ecological invasion. Nature 417:636-638.

Le Roux, P. C., and M. A. McGeoch. 2010. Interaction intensity and importance along two stress gradients: adding shape to the stress-gradient hypothesis. Oecologia 162:733-745.

Leonard, G. H. 2000. Latitudinal variation in species interactions: A test in the New England rocky intertidal zone. Ecology 81:1015-1030.

Lockwood, J. L., M. F. Hoopes, and M. P. Marchetti.2013. Invasion ecology. Second edition. Wiley-Blackwell, Hoboken, New Jersey, USA.

Lortie, C. J., and R. M. Callaway. 2006. Re-analysis of metaanalysis: support for the stress-gradient hypothesis. Journal of Ecology 94:7-16.

Maestre, F. T., F. Valladares, and J. F. Reynolds. 2005. Is the change of plant-plant interactions with abiotic stress predictable? A meta-analysis of field results in arid environments. Journal of Ecology 93:748-757.

Maestre, F. T., R. M. Callaway, F. Valladares, and C. J. Lortie. 2009a. Refining the stress-gradient hypothesis for competition and facilitation in plant communities. Journal of Ecology 97:199-205.

Maestre, F. T., I. Martínez, C. Escolar, and A. Escudero. 2009 b. On the relationship between abiotic stress and co-occurrence patterns: an assessment at the community level using soil lichen communities and multiple stress gradients. Oikos 118:1015-1022.

Maron, J. L., and M. Vila. 2001. When do herbivores affect plant invasion? Evidence for the natural enemies and biotic resistance hypotheses. Oikos 95:361-373.

McAfee, D., and M. J. Bishop. 2019. The mechanisms by which oysters facilitate invertebrates vary across environmental gradients. Oecologia 189:1095-1106.

McQuaid, C. D., and G. M. Branch. 1984. Influence of sea temperature, substratum and wave exposure on rocky intertidal communities - An analysis of faunal and floral biomass. Marine Ecology Progress Series 19:145-151.

Menge, B. A., and G. M. Branch. 2001. Rocky intertidal communities. Pages 221-251 in M. D. Bertness, S. D. Gaines and M. E. Hay, editors. Marine community ecology. Sinuaer Associates, Sunderland, Massachusetts, USA.

Menge, B. A., and J. P. Sutherland. 1987. Community regulation: variation in disturbance, competition, and predation in relation to environmental-stress and recruitment. American Naturalist 130:730-757.

Michalet, R., R. W. Brooker, L. A. Cavieres, Z. Kikvidze, C. J. Lortie, F. I. Pugnaire, A. Valiente-Banuet, and R. M. Callaway. 2006. Do biotic interactions shape both sides of the humped-back model of species richness in plant communities? Ecology Letters 9:767-773.

Northfield, T. D., S. G. Laurance, M. M. Mayfield, D. R. Paini, W. E. Snyder, D. B. Stouffer, J. T. Wright, and L. Lach. 2018. Native turncoats and indirect facilitation of species invasions. Proceedings of the Royal Society B 285:20171936.

Qi, M., T. Sun, S. F. Xue, W. Yang, D. D. Shao, and J. Martinez-Lopez. 2018. Competitive ability, stress tolerance and plant interactions along stress gradients. Ecology 99:848857.

Ruesink, J. L. 2007. Biotic resistance and facilitation of a nonnative oyster on rocky shores. Marine Ecology Progress Series 331:1-9.

Sandrini-Neto, L., and M. G. Camargo. 2012. GAD: Analysis of variance from general principles. $\mathrm{R}$ package version 1.1.1. https://cran.r-project.org/web/packages/GAD/index.html

Silliman, B. R., M. D. Bertness, A. H. Altieri, J. N. Griffin, M. C. Bazterrica, F. J. Hidalgo, C. M. Crain, and M. V. Reyna. 
2011. Whole-community facilitation regulates biodiversity on patagonian rocky shores. PLoS ONE 6:10.

StamenDesign. 2016. Stamen Design: data visualization and map sesign studio. Stamen Design Studio, San Francisco, California, USA.

Stickle, W. B., E. Carrington, and H. Hayford. 2017. Seasona changes in the thermal regime and gastropod tolerance to temperature and desiccation stress in the rocky intertidal zone. Journal of Experimental Marine Biology and Ecology 488:83-91.

Stachowicz, J. J., H. Fried, R. W. Osman, and R. B. Whitlatch. 2002. Biodiversity, invasion resistance, and marine ecosystem function: reconciling pattern and process. Ecology 83:25752590.

Stillman, J. H., and G. N. Somero. 2000. A comparative analysis of the upper thermal tolerance timits of Eastern Pacific Porcelain crabs, genus Petrolisthes: influences of latitude, vertical zonation, acclimation, and phylogeny. Physiological and Biochemical Zoology 73:200-208.

Tweedley, J. R., E. L. Jackson, and M. J. Attrill. 2008. Zostera marina seagrass beds enhance the attachment of the invasive alga Sargassum muticum in soft sediments. Marine Ecology Progress Series 354:305-309.

Underwood, A. J. 1997. Experiments in ecology: their logical design and interpretation using analysis of variance. Cambridge University Press, Cambridge, UK.

Wright, J. T., and P. E. Gribben. 2017. Disturbance-mediated facilitation by an intertidal ecosystem engineer. Ecology 98:2425-2436.

Wright, J. T., P. E. Gribben, and S. Latzel. 2016. Native ecosystem engineer facilitates recruitment of invasive crab and native invertebrates. Biological Invasions 18:3163-3173.

Wright, J. T., Z. C. Holmes, and J. E. Byers. 2018. Stronger positive association between an invasive crab and a native intertidal ecosystem engineer with increasing wave exposure. Marine Environmental Research 142:124-129.

Zhang, G. F., W. Z. Zhao, H. Zhou, Q. Y. Yang, and X. F. Wang. 2018. Extreme drought stress shifts net facilitation to neutral interactions between shrubs and sub-canopy plants in an arid desert. Oikos 127:381-391. 